\title{
ANÁLISE DO PROGRAMA BOLSA FAMÍLIA PARA POVOS INDÍGENAS A PARTIR DA NOÇÃO DE DESENVOLVIMENTO
}

\author{
MARINA BOZZETTO ${ }^{1}$
}

\begin{abstract}
Resumo: A partir de revisões bibliográficas, este artigo busca discutir e problematizar a noção de desenvolvimento, mais especificamente os paradoxos que ela traz nas políticas para povos autóctones, exemplificados no Programa Bolsa Família dirigido para os indígenas e em suas condicionalidades de educação. No primeiro momento, se fará uma exposição das ideias da noção "desenvolvimento"; após, será contextualizada e exemplificada a prática dessa ideia de desenvolvimento pela concepção e aplicação do Programa Bolsa Família e de suas consequências, desenvolvendo uma de suas principais condicionalidades, a educação; e por fim, serão pontuadas brevemente al gumas tentativas do antropólogo de se colocar diante dessa encruzilhada e paradoxo.
\end{abstract}

Palavras-chave: Programa Bolsa Família; Noção de Desenvolvimento; Povos Indígenas.

De início, gostaria de ressaltar que, apesar de ser contra agrupar "povos indígenas” em uma só categoria, devido à sua diversidade de povos, histórias, culturas, relações, entre outros, neste texto fiz a escolha de abarcar e utilizar o termo "indígenas" como um grupo. A escolha desta categoria se deu pelo próprio objeto que me propus a estudar - Programa Bolsa Família - pelo mesmo em seu início não fazer as diferenciaçôes por povos. Apesar disso, em alguns pontos irei especificar um ou outro povo e local.

Para início, alguns conceitos são importantes de se explicitar. O primeiro é a ideia de "desenvolvimento". Esse conceito não consiste nem numa definição fixa, nem está vazia de significados e de políticas intrínsecas que guiam as políticas governamentais. Pelo contrário,

\footnotetext{
1 Graduanda em Ciências Sociais pela Faculdade de Filosofia, Letras e Ciências Humanas da Universidade de São Paulo (FFLCH/USP).

marina.bozzetto@usp.brou maribzztt@gmail.com
} 
ela contém em si uma rede de discursos (RIBEIRO, 2008) e um contexto político, cultural e social a partir de "uma visão de mundo específica e particular” (PERROT, 2008, p. 222).

A concepção de desenvolvimento se dá a partir da relação de transformação sistemática das relações sociais e da natureza. Ela deve ser entendida numa relação de jogo de forças ao longo da história a partir de seu caráter de poder. De acordo com Perrot, a noção de desenvolvimento está fundada em três pilares próprios ao Ocidente: Aristóteles, o judaico-cristianismo e a ideologia do Iluminismo, ou seja, ele segue uma lógica, linearidade e racionalidade, aparecendo como "natural, desejável e inevitável” (PERROT, 2008, p. 220)

O problema surge quando se começa a estudar e pensar os povos indígenas a partir dessa concepção, pois pensar o desenvolvimento para tais povos é transpor modelos de sociedades do Ocidente como se fossem universais, ou seja, como evidenciado por Perrot, pensar o desenvolvimento para os indígenas pode nos tender a projetar modelos e valores que acreditamos valer para todos. (PERROT, 2008)

Com isso, alguns princípios fundamentais, como o de autodeterminação e de autonomia “estariam ameaçados, desde o início, pelo próprio 'direito ao desenvolvimento' - ri gor de um disfarce retórico da obrigação e do 'dever do desenvolvimento"” (BARRETO, 2006, p. 16-17).

Deve-se ter cuidado, porém ao analisar essa problemática, pois, o "desenvolvimento" por si só não é destruidor necessariamente por ameaçar os modos de vida dos "povos tradicionais". Seu problema se encontra em exigir em sua lógica a abundância material excessiva a partir da destruição do outro (PERROT, 2008, p. 231). A partir, então, desta afirmação e deste contexto, problematizarei nesse texto a aplicação do programa Bolsa Família. Não por não concordar com o programa em si, mas sim por querer discutir e exemplificar o entrave que é o desenvolvimento ser apresentado como um projeto de melhoria social. 
O Programa Bolsa Família foi criado em 2003 pelo Ministério do Desenvolvimento Social ${ }^{2}$ e consiste na transferência monetária às famílias em condições de pobreza e extrema pobreza a partir de um sistema de condicionalidade de saúde e educação.

Tal política social, em parceria com a Fundação Nacional do Índio - FUNAI, começou também a abranger as populações indígenas que viviam em situaçôes de vulnerabilidade, com estas sendo consideradas públicos prioritários. E, em 2012, foi estruturado o Programa de Proteção e Promoção dos Direitos dos Povos Indígenas

Apesar de ser aplicado de forma diferenciada a essas populações, o Programa possui as mesmas concepções, sendo esse o principal ponto problemático. Com isso, apesar de representar por um lado melhorias para os indígenas - com estes reivindicando a permanência de tal política - representa, por outro lado, problemas e consequências negativas para as aldeias e as pessoas.

A partir dessa constatação, esta parte do artigo busca analisar a aplicação desse programa pensando-o como um paradoxo que, ao mesmo tempo que tenta amenizar os impactos e vulnerabilidades de um "desenvolvimento forçado", faz parte de um projeto desenvolvimentista, começando pela própria noção básica para o Programa do que é pobreza.

O PBF se objetiva a superar a extrema pobreza, usando a renda como critério para seu funcionamento. No entanto a própria concepção de pobreza como um conceito economicista deve ser questionado, representando este um entrave para sua aplicação aos povos indígenas ${ }^{3}$.

De acordo com os Relatórios dos Estudos Etnográficos sobre o Bolsa Família entre Povos Indígenas, publicado pelo Ministério do Desenvolvimento Social e Agrário (VERDUM - Relatório Final, 2016), a maioria dos indígenas não compartilhavam da mesma noção de pobreza que as culturas ocidentais, não tendo muitas vezes sentido em suas línguas.

$\mathrm{Na}$ língua dos Apanyekra Canela, por exemplo, não há nenhuma palavra equivalente ao termo "pobreza”. Segundo os mesmos, sua ideia está relacionada à problemas de escassez em relação às festas, quando a comunidade não consegue realizar seus amekin. Para

2 O Ministério do Desenvolvimento Social foi incorporado ao Ministério da Cidadania, e se criou a Secretaria Especial do Desenvolvimento Social (MEDIDA PROVISÓRIA № 870, DE 1 DE JANEIRO DE 2019).

3 Em metodologias de programas sociais, a definição de pobreza perpassa principalmente pela insuficiência de renda, e, quando analisado para além desse critério (acesso a conhecimento, saúde, etc), a definição é cons truída a partir de indicadores escalares sem uma discussão qualitativa de cada caso. (BARROS; CARVALHO; FRANCO, 2003) 
além disso, "os Apanyekra [...] se diziam comparativamente mais 'pobres' que os brancos pelo motivo de não produzirem as invenções dos não indígenas - uma pobreza relacional” (VERDUM - Relatório Final, 2016, p. 39).

Tal conceito como relacional aos brancos aparece constantemente nos relatórios dos Estudos Etnográficos.

Quando chegam a acionar o termo “pobreza” segundo as conceituações de não in dígenas, [...] o fazem dentro de um quadro de compreensão específico. Um exemplo disso é a maneira como atribuem significado e se relacionam com o "dinheiro". Ele é visto como algo necessário, notadamente quando as pessoas estão na cidade; nesse contexto, ter ou não ter "dinheiro" traz efeitos importantes e sua ausência pode causar sofrimento, como "sede" e "fome". (VERDUM - Relatório Final, 2016, p.70)

\section{Em outro momento:}

A pobreza é entendida como algo que veio de fora, foi trazido pelos "waradzu” ("não índios”) e existe na medida em que é associada aos brancos, pois os Xavante não podem adquirir itens de vestuário, por exemplo, "por essa parte somos pobres”, ou seja, são pobres porque não dispõem de recursos para adquirir as roupas que foram introduzidas nas aldeias pelos brancos (VERDUM - Relatório Final, 2016, p.84)

Tais passagens demonstram como o termo e condição de pobreza são vistos em relação aos brancos, como algo trazido por eles, e, utilizar tal conceito econômico e monetário como base do Programa representa um problema de concepção e prática, mostrando como acaba se impondo sobre a população indígena como um projeto desenvolvimentista ${ }^{4}$.

Por outro lado, ele se propóe a resolver problemas reais causados pelo "desenvolvimento", sendo necessário e reivindicado pelas populações indígenas como, inclusive, obrigação dos brancos. Para tentar resolver tal paradoxo, portanto, alguns consultores colocam "a necessidade de um Programa específico para populações indígenas, formulado em outras bases conceituais que não as de 'pobreza' ou de 'extrema pobreza'”. (VERDUM - Relatório Fi-

4 Projeto desenvolvimentista por ser entendido como "a política econômica formulada e/ou executada, de forma deliberada, por governos (nacionais ou subnacionais) para, através do crescimento da produção e da produtividade, sob a liderança do setor industrial, transformar a sociedade com vistas a alcançar fins desejáveis, destacadamente a superação de seus problemas econômicos e sociais, dentro dos marcos institucionais do sistema capitalista.” (FONSECA; 2013; p. 40) 
nal, 2016, p.71), já que muitos problemas não precisariam ser resolvidos via repasse financeiro, e sim com postos de atendimento, por exemplo.

Outro aspecto que traria contradições seria a própria "monetarização das relações sociais nas aldeias" (GALLOIS, ROSALEN, 2016, p. 34). O repasse de renda às pessoas causa diversos problemas, como o incentivo para políticas voltadas aos indivíduos em contraposição às políticas de "reconhecimento de direitos coletivos" (GALLOIS, ROSALEN, 2016, p. 34) que futuramente garantiria uma maior luta pelos direitos de terra, por exemplo, ou a fixidez dessas duas categorias - coletivo e indivíduo - sem considerar as dinâmicas culturais internas.

Outro problema seria o êxodo de jovens das terras indígenas às cidades próximas. Uma reportagem feita pela TV Folha em 2016 sobre o PBF para os indígenas na região do Xingu coloca alguns dos efeitos sobre a política, dentre eles, esse deslocamento. $\mathrm{Na}$ reportagem, os indígenas entrevistados logo começam questionando - como acima - o que seria ser pobre, colocando essa categoria como uma visão ocidental imposta às comunidades.

De acordo com os entrevistados nessa reportagem, o PBF é necessário dentro da comunidade, então mais uma vez exaltado como necessário - já que os problemas não estavam ligados exclusivamente a ele - no entanto, enquanto ele ajuda em situaçóes como comprar itens que a população necessita na aldeia, por exemplo, ele também cria outros problemas.

O Programa cria, por exemplo, a necessidade de se deslocarem das aldeias às cidades todo mês, mesmo em regióes mais afastadas onde esse deslocamento pode levar até 10 dias de viagem. Com isso, as pessoas começaram a se mudar para as cidades, causando um certo esvaziamento das aldeias e mudanças de hábitos. Alguns trechos da reportagem realizada pela TV Folha evidenciam esse problema:

O secretário-executivo do Instituto Socioambiental, André Villa-Bôas, fala que “a Bolsa Família impõe um cronograma de ir às cidades retirar o benefício [...] , cria a obrigação de ir para a cidade todo mês”. Em outro momento, o morador do Xingu e funcionário da Funai Ianukula Kaiabi Suía diz "algumas famílias já se deslocaram para ficar algum tempo na cidade por conta desse benefício.” (TV FOLHA, 2016)

Duas moradoras da cidade de Canarana, Yamata Lia Kuikuro e Leiru Mehinaku, relatam, respectivamente, que: “antes eu morava na aldeia, eu vinha para cá de carona mas eu não preciso pagar o aluguel com esse dinheiro, eu só gasto cuidando das minhas crianças” e "quando eu morava na aldeia, eu tinha muito pouco, lá a gente não precisa de dinheiro, mas quando você está aqui na cidade, você fica com o dinheiro um pouco e depois acaba, isso que é difícil.” (TV FOLHA, 2016). 
Análise do Programa Bolsa Família para povos indígenas a partir da noção de desenvolvimento

Em outro momento da mesma reportagem, Marcelo Kamayurá, morador de Xingu, fala:

Nossa preocupação enquanto lideranças é que esse pensamento de ir morar na cidade para poder sobreviver com o Bolsa Família ou aposentadoria pode despovoar as nossas comunidades. Encaminhar um jovem para estudar, para se formar, tudo bem, mas quando ela retornar, ela vai aplicar todo o seu conhecimento em pró da comunidade, vai ajudar a comunidade. (TV FOLHA, 2016).

Outro trecho importante de se ressaltar da reportagem é uma das falas do Douglas Rodrigues, médico e professor da UNESP:

O problema não é você ter um programa [...] como o Bolsa Família. O problema era não ter nenhuma sensibilidade cultural. O mesmo Bolsa Família que vem para cá é o Bolsa Família que vai para as áreas urbanas. [...] Um programa como esse [...] tem que ser pensado com muito cuidado ao intervir em situaçóes socioculturalmente distintas. (TV FOLHA, 2016)

Ou seja, o PBF enquanto foi trazido para as populações indígenas como uma resposta - necessária - aos problemas das políticas assimilacionistas, genocidas e etnocidas, também trouxe outras consequências, já que foi desenvolvido e aplicado como um projeto desenvolvimentista desde sua concepção política com termos e medidas, mostrando também, portanto, que uma política única não é o suficiente.

Ademais dessas discussóes, o PBF tem - como citado acima - como modelo a transferência monetária condicionada, sendo, neste caso, a saúde e educação as condições. Ou seja, para receber os benefícios, as crianças de 6 a 17 anos devem frequentar a escola, e deve-se manter a vacinação em dia, além da necessidade das grávidas fazerem um exame pré-natal e de acompanhamento. Caso tais condições não sejam cumpridas, o benefício é suspenso, o que deveria dar um caráter de exigência ao Estado de atender as demandas que o próprio governo cobra.

Uma das principais condicionantes, e que será explorada aqui, é a de educação. Segundo Relatório Final dos Estudos Etnográficos sobre o Programa Bolsa Família entre Povos Indígenas, as percepções que os povos indígenas possuem sobre ela é que, às vezes - e jun to à de saúde - elas representam mais um obstáculo para o PBF do que realmente é positivo para as terras indígenas.

Dentre os apontados, parte são problemas que se enfrentam na educação do país como um todo, e parte são problemas de logística - como a grande distância que se mantém 
entre as aldeias e as escolas em alguns casos - e de atendimento muito rígido dentro das Terras Indígenas, tendo muitas vezes um difícil diálogo levando em conta os problemas e contextos da aldeia e de cada família.

Dentre as dificuldades de lidar com os contextos culturais, está a diferença de percepção, por exemplo, há famílias que consideram mais importante as crianças participarem da colheita e plantio do que irem à escola em determinados períodos; ou coisas mais cotidianas, por exemplo, de que comumente entre os Kaiowá e Guarani, sempre que o dia amanhece chovendo, se cancela todos os compromissos (VERDUM - Relatório Final, 2016).

Todavia, para além desses apontamentos que se faz sobre as condições que se dá a cobrança de tal condicionalidade, vale questionar a própria aplicação da educação como um todo, de qual seria talvez a melhor - ou menos problemática - forma, já que, como dito inclu sive no Relatório de Verdum, “a escolarização parece ser, por vezes, compreendida como uma concessão que se faz ao governo, por receber o PBF, e não um efetivo caminho de 'ascensão social'” (VERDUM - Relatório Final, 2016, p. 58).

Uma das bases dos projetos educacionais para os povos indígenas atualmente é a interculturalidade, e junto dela, os princípios de "valorização da cultura 'nativa' e o desenvolvimento das populações indígenas.” (COLLET, 2006, p. 117).

De acordo com a autora, a política indigenista latino-americana teve grande influência da SIL Internacional ${ }^{5}$, esta atuando com educação bilíngue e intercultural. Atualmente, no entanto, a maioria dos projetos educacionais indígenas criticam tais posições da SIL, já que se fala que era “a serviço da integração civilizatória e cristianizante” (COLLET, 2006 , p. 116). Apesar, e contraditoriamente a isso, mesmo os projetos críticos, mantiveram a questão da interculturalidade como princípio, nos fazendo questionar, assim como também levantado pela autora, o quão democrático e autônomo esses projetos são e o que está por trás dessa interculturalidade, já que esta foi “inventada” e praticada em projetos missionários.

A interculturalidade é baseada na troca de conhecimentos entre os brancos e os índios em forma de diálogo com o discurso de coexistência entre os dois modos de vida. Ela tem como princípio o respeito e valorização das diferenças, se firmando na formação de professores e currículo diferenciado que contemple as diversidades culturais, tratando-as, portanto, como enriquecedor e não um obstáculo para a convivência. (COLLET, 2006)

Quanto a essa discussão,

5 Antiga Summer Institute of Linguistics, e chamada em português de Sociedade Internacional de Linguística 
Análise do Programa Bolsa Família para povos indígenas a partir da noção de desenvolvimento

na Europa convivem dois pontos de vista. Um deles aposta na 'educação intercultural' como um avanço em relação às políticas assimilacionistas anteriores. O outro ponto de vista considera que a 'educação intercultural' é apenas uma adequação às mudanças que têm ocorrido no mundo nas últimas décadas, as quais seguiram um modelo "neoliberal" de dominação, que, sob aparência de inclusão, excluiriam cada vez mais certas parcelas da população. (COLLET, 2006, p. 116)

Apesar de, como colocado acima, os projetos com a visão intercultural e não mais de caráter integracionista, poderem representar um avanço, as concepções e práticas desse próprio princípio pode resultar nesse caráter anterior, que ainda estaria por detrás dos projetos atuais.

O problema que pode-se colocar quanto a essa educação diferenciada para os indígenas, é o quanto de diálogo é possível se travar entre "os dois mundos". Como coloca a autora acima, enaltecer as diferenças pode significar o apagamento artificial das desigualdades sociais e políticas dos atores.

Para além disso, com a valorização da cultura a partir de um tipo de currículo e tipo de conhecimento específico do mundo dos não-indígenas - que de fato na maioria das vezes não condiz com os tipos de conhecimentos dos índios - acaba por descontextualizar politicamente a cultura, criando imagens caricatas, ou como poderia ser chamado, de "folklorização da cultura", onde a simplificação da cultura seria feita para fins políticos e econômicos (COLLET, 2006, p. 125-126), além de traçar os povos como diferentes resultando possivelmente numa exclusão maior ainda.

Assim como colocado anteriormente, na Europa as visóes sobre o caráter ainda integracionista e desenvolvimentista dos novos projetos baseados na interculturalidade ou não, para os indígenas também ocorre essa dupla reação.

\footnotetext{
Se, por um lado, grande parte dos grupos indígenas vêem a educação intercultural como forma de inserção na sociedade e economia nacionais, por outro lado há os que sentem nesse tipo de proposta uma visão discriminatória e excludente. Estes últimos querem a escola da aldeia nos mesmos moldes da escola do branco, com o mesmo material e os mesmos conteúdos curriculares. (COLLET, 2006, p. 125)
}

O grupo de indígenas que não concordariam com tal forma de educação diferenciada reivindicariam que se tenha nos locais o mesmo tipo de escolas que se tem para os brancos, pois os conhecimentos acerca de suas próprias culturas se dariam de outras formas, reservando o conhecimento/método dos brancos ao "currículo dos brancos". 
O PBF é benéfico e reivindicado pelos indígenas, no entanto ele também coloca consequências e está num contexto de projeto desenvolvimentista, cabendo então ao antropólogo a necessidade de se colocar nesse entrave. Especificamente sobre o Programa, os consultores sugerem ao Ministério do Desenvolvimento Social que se crie um campo de reflexão parti cipativo para que o PBF tenha regras e procedimentos específicos aos povos indígenas, havendo uma reformulação da visão do mesmo.

Mas, para além de pontos mais específicos como o caso do Programa Bolsa Família ou ao próprio modelo de educação, discutido nas condicionalidades, é importante que se coloque o papel do antropólogo na luta pelos indígenas e contra o desenvolvimentismo. Os autores abordados ao longo do ensaio, colocam algumas tarefas tanto dos antropólogos nãoindígenas quanto dos que são.

\section{ANTROPÓLOGOS E ANTROPOLOGIA}

Quanto à disciplina Antropologia, alguns autores como Barreto e Santos se propóem a fazer um novo método antropológico - chamada de antropologia cruzada - em que se teria um exercício de reflexividade, com a inversão dos papéis relacionais, pois "se isso, por si só, não define uma simetria da relação, pelo menos possibilita um movimento circular no processo de aprendizado" (BARRETO, SANTOS, 2017, s/p).

Para os indígenas, alguns autores colocam como sendo uma estratégia possível a partir dos entraves traçados, eles alcançarem a autonomia utilizando-se de armas próprias dos brancos, por exemplo o uso de seu currículo educacional para adentrar este campo. "Agora já perdemos tudo e estamos virando brancos [...] agora é com a arma dos conhecimentos dos brancos que estamos voltando a ser índios” (TV FOLHA, 2016). 
Análise do Programa Bolsa Família para povos indígenas a partir da noção de desenvolvimento

REFERÊNCIAS BIBLIOGRÁFICAS

ALMEIDA, M. W. B. de. Caipora e outros conflitos ontológicos. Revista de Antropologia da UFSCar, v.5, n.1, jan.-jun. p.7-28, 2013.

BARRETO, H. T. Os predicados do desenvolvimento e a noção de autoctonia. Tellus, ano 6, vol.10, 2006.

BARRETO, J. P. L.; SANTOS, G. M. A volta da Cobra Canoa: em busca de uma antropologia indígena. Revista de Antropologia, vl. 60/1, p. 84-98, 2017.

BARROS, R. P; CARVALHO, M.; FRANCO, S. O indice de desenvolvimento da Familia (IDF). Texto para Discussão no 986. Rio de janeiro, 2003.

COLLET, C. L. G. Interculturalidade e educação escolar indígena: um breve histórico. In: GRUPIONI, L. D. B. (Org.). Formação de professores indigenas: repensando trajetórias. Brasília: MEC-SECAD-UNESCO, 2006.

FONSECA, P. C. D. Desenvolvimentismo: a construção do conceito. Textos para Discussão, IPEA, 2013.

GALLOIS, D. T. A escola como problema: algumas posições. In: CUNHA, M. C. da; CESARINO, P. de N. (Org.) Politicas culturais e povos indígenas. São Paulo: Ed. Cultura Acadêmica, UNESP, 2014, Cap. 19,.

GALLOIS, D. T.; KLEIN, T.; DAL’ BO, T. L. Povos Indígenas, Políticas Multiculturais e Políticas da Diferença. Revista de Cultura e Extensão USP, [S. l.], v. 15, p. 31-48, 2016.

GALLOIS, D. T.; ROSALEN, J. Direitos indígenas 'diferenciados' e seus efeitos entre os Wajãpi no Amapá. Dossiê Antropologia do Direito no Brasil. 2016.

LANGDON, E.; DIEHL, E. Participação e Autonomia nos Espaços Interculturais de Saúde Indígena: reflexões a partir do Sul do Brasil. Saúde e Sociedade, São Paulo 16.2: 19-36. 2007. 
PERROT, D. Quem impede o desenvolvimento circular? Desenvolvimento e povos autóctones, paradoxos e alternativas. Revista Cadernos de Campo, n.17, p. 219-232, 2008.

RIBEIRO, G. L. Poder, redes e ideologia no campo do desenvolvimento. Novos estudos CEBRAP, v. 80, 2008

TV FOLHA. Bolsa Familia altera rotina de indigenas no Xingu. Setembro, 2016. Disponível em https://www.youtube.com/watch?v=wI8WqUPDUys. Acesso em 15 jul. 2018

VERDUM, R. Estudos etnográficos sobre o Programa Bolsa Família entre povos indígenas. Brasília: MDS, 2016.

VERDUM, R. Estudos etnográficos sobre o Programa Bolsa Familia entre povos indígenas. Relatório Final. Brasília: MDS, 2016. 